\title{
Real institutions, real talk \\ Reflecting on over a decade of diversity scholars visits to ARL research libraries
}

A $s$ part of Association of Research Libraries' (ARL) Initiative to Recruit a Diverse Workforce (IRDW) recruitment program, Diversity Scholars visit an ARL library to observe, firsthand, the realities of academic librarianship. This article presents three perspectives on more than a decade of site visits, which bring together library school students from traditionally underrepresented groups and research library professionals.

First, ARL Program Director Mark A. Puente provides a history of these visits. Next, a committee chair at a site location reflects upon ten years of Purdue University visits from 2005 to 2014. Lastly, an IRDW Diversity Scholar describes her experience participating in two visits, first as a student and then as a member of the site visit planning committee at Michigan State University, which hosted the visit in 2015 and 2016.

"Initiative to Recruit a Diverse Workforce: History of the Program"-Mark A. Puente, director of diversity and leadership programs, ARL

Over the last 18 years, there have been many programs established that seek to recruit people from historically underrepresented racial and ethnic groups into the library profession. The designs of many of these programs have been quite similar, providing funding for graduate-level master of library and information science (MLIS) education, leadership development, mentorship, and other components that serve to establish peer networks and to ensure the academic success of these students as well as support their transitions into the professional workforce.
In 2000, ARL established its IRDW when 52 member institutions created a fund to underwrite the program. From the moment IRDW was established, the focus, in terms of recruitment and continuing education content, has been on the academic/research library environment. The ARL IRDW program was subsequently supported by three grants from the Institute of Museum and Library Services awarded in 2003, 2006, and 2010.

To a great degree, the objective of the program has been less on recruiting and supporting diverse students who may have been considering other career paths, and more on supporting and encouraging those already in the MLIS pipeline to consider careers in research libraries. To this end, in 2005, a component was added to the overall design of IRDW to complement the existing elements. It was then that ARL member institutions began providing a site visit experience to a major research library for the IRDW participants.

In 2005, both the Harvard College Libraries (HCL) and the Purdue University Libraries hosted Diversity Scholars for a multiday event. The Harvard visit included scholarship recipients of ALA's Spectrum Scholarship Program.

Ilana R. Stonebraker is assistant professor of library science, Purdue University, email: stonebraker@purdue. edu, Ebony Magnus is assessment and user experience librarian at SAIT Polytechnic, email: ebonymagnus@ gmail.com, and Mark A. Puente is director of diversity and leadership programs at the Association of Research Libraries, email: mpuente@arl.org

(C) 2016 Ilana R. Stonebraker, Ebony Magnus, and Mark A. Puente 
For the Purdue program, according to its main champion, Dean James Mullins, the "research library visit" was intended to provide a unique perspective to these neophyte LIS professionals. The goal was to provide an inside view of the operations of a major research library, but within the context of a large, Midwestern institution of higher learning. The Purdue library visit was unique as well given the campus' orientation toward scientific and technological curricula and the fact that the majority of librarians are on tenure-track faculty appointments.

The MIT libraries collaborated with HCL in 2008 for a joint visit where attendees spent a day on each campus. The project was initiated out of a retreat of the MIT Library Council (consisting of department heads and associate/ assistant directors) that was focused, in part, on issues of recruitment of diverse staff. According to MIT's FY09 Annual Report,

[participants] were provided a glimpse into the dynamic and distinctive environments of these two world-renowned institutions. Extensive staff participation from both libraries provided guests the opportunity to interact directly with those who have chosen academic librarianship and to hear some of the reasons so many professionals are drawn to these stimulating environments.

The Purdue library visits would continue for a span of ten years, after which the Michigan State University Libraries (MSU) began hosting the visit. The MSU libraries were selected for the event in 2014 after a competitive application and selection process that was open to all ARL member libraries.

\section{"Ten Years of Campus Visits at Purdue"-Ilana} Stonebraker, assistant professor, Purdue Libraries From 2005 to 2014, Purdue Libraries hosted the annual research library visit. The Purdue University Libraries visits contrasted with the Harvard/MIT visits in that the setting was in a non-urban, college town environment where (as posited by Dean Mullins) it is especially difficult to recruit diverse talent. This visit was designed to provide an inside look at a major research library in the Midwest. As part of their visit, ARL Diversity Fellows learned about Purdue as case study for the roles, organizational structure, and planning processes that comprise a research library system. Itineraries usually included an introduction to promotion and tenure at Purdue, as well as to various research initiatives at Purdue. Representatives from cultural centers at Purdue met with the students for lunch or a meeting. The itineraries included a visit with a provost or vice provost to examine the relationship between a research library and its parent institution. A highlight for the IRDW scholars was a dinner and reception, where Mullins opened his home to the students.

Starting in 2007, Purdue completed an assessment of the program following each visit. Of the 78 library scholars who evaluated the visits, 77 said it met their expectations, with one neutral. The enthusiasm for the visit was reflected in scholars' comments:

I enjoyed having access to Purdue's librarians and administration. I also deeply respect and appreciate Dean Mullins opening his home to ARL's Diversity Scholars.—IRDW Scholar, 2013

The willingness of PUL faculty to give their time and share their experiences candidly with us. The honesty you displayed in our conversations. The welcome we felt. The VERY nice hotel we were able to stay in. The inclusion of circAfrique as entertainment. Really, there were so many positive experiences in the visit, it's hard to narrow it down to just one or two.-IRDW Scholar, 2009

I was involved with the program in 2013 and chair in 2014. From my perspective, the IRDW Scholar Visit was always a chance for me to learn from and network with the students. As a newer librarian at the time, I identified with the scholars who were searching for connections and meaning as they entered into the profession. 


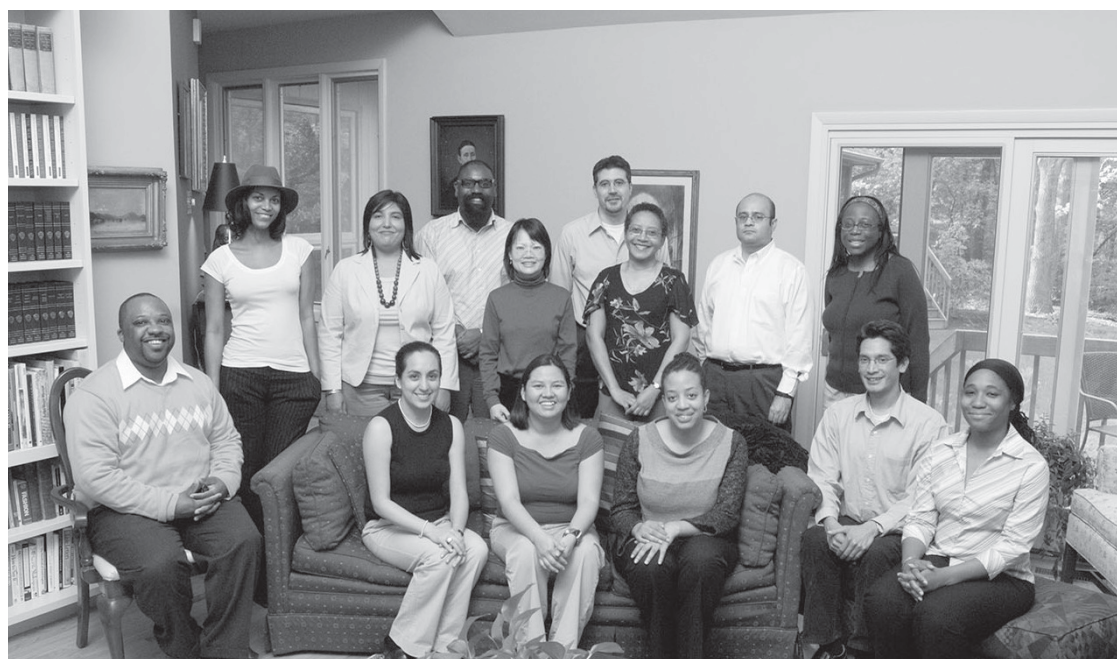

2006 ARL IRDW Scholars Visit at the Purdue. Picture taken at Dean Mullin's home. Front row: Jerome Offord, Claudia Sueyras, Valerie Yazza, Latanya Jenkins, Megan Perez, Deborah Lilton. Second row: Jason Beatrice Lee, Marissa Alcorta, Khan Berg (Nguyen), Yasmin Morais, Liladhar Pendse, Miriam Bridges. Third row: Third row: Douglas Lyle, David Fernandez-Barrial.

"From Visitor to Host: One Scholar's Perspective"-Ebony Magnus, 2012-14 IRDW Scholar; assessment and user experience librarian, SAIT Polytechnic

I visited Purdue University Libraries in April 2013 as a 2012-14 IRDW Diversity Scholar. My peers and I were welcomed warmly and treated like VIPs as we met and learned from many Purdue librarians and library and campus administrators.

We toured existing spaces and saw plans for new active learning environments, we learned about the development and implementation of programs and services like IMPACT (Instruction Matters: Purdue Academic Course Transformation) and PURR (Purdue University Research Repository), and we conversed with library professionals as though we were already professionals ourselves. Between sessions and at mealtimes, I met people who took an interest in my professional goals and generously gave advice and shared information. I don't know that it should have, but what surprised me most about these interactions was the feeling that I was an equal participant in these dialogues, with valued experiences to contribute. In my experience as a library school student, these feelings of inclusion, mutual respect, and collegiality were not a given in all my interactions with professionals-making it all the more impactful at Purdue.

One session in particular sticks in my mind. We scholars met privately with the vice provost for diversity and inclusion, with whom we were able to ask candid questions and discuss the realities of working at a large research institution in a university town. The security and freedom that we felt in that environment and at Purdue in general is something that the Michigan State University (MSU) Libraries tried to emulate when planning to host its site visit.

I graduated from library school with the distinct sense that this profession-and especially the ARL membership-had invested in me. The generosity of time and experience shown by Purdue's librarians to me and my peers left me with a strong desire to pay it forward. At the risk of sounding overly effusive, I was nothing short of thrilled to learn in late 2014 that my then employer, the MSU Libraries, would be hosting the 2015 and 2016 IRDW site visits. In 2013, MSU hired three IRDW scholars in a single year.

With this in mind, the libraries' administra- 


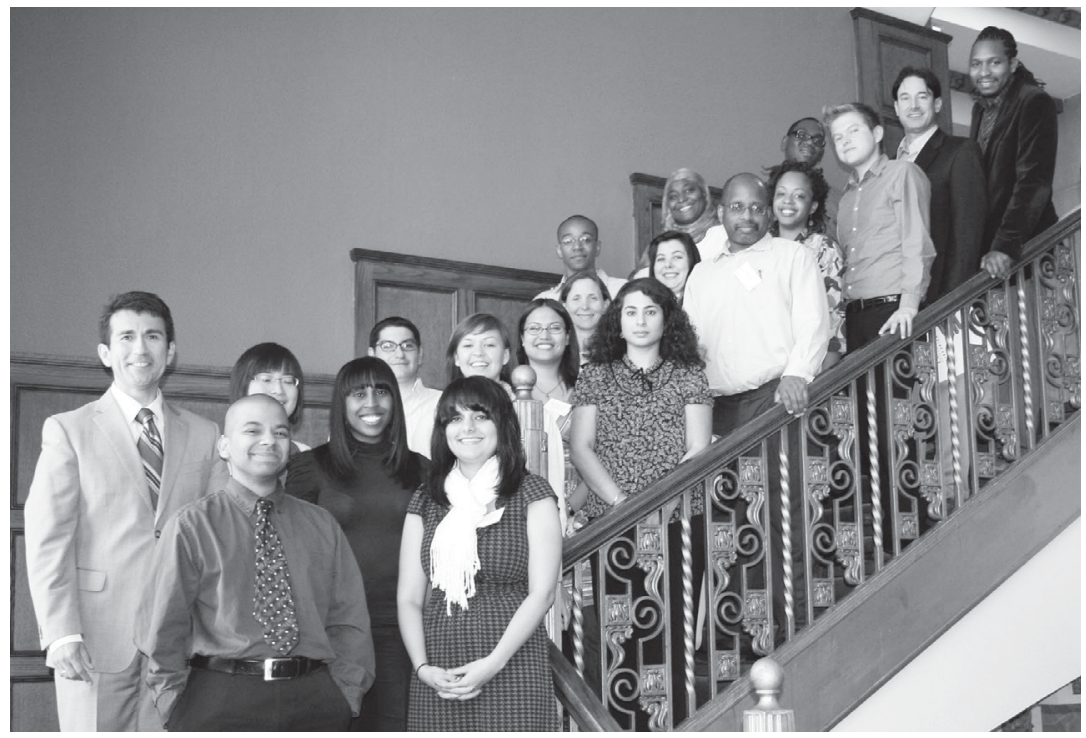

2010 ARL IRDW Diversity Scholars Visit at Purdue. Program Director Mark A. Puente, Scholars Samip Mallick, Stacy Harris, Sheetija Kathuria, Xiaomei Gu (hiding), Roy Brooks, Jennifer Huck, Laksamee Putnam, Marcela Estevez, Langston Bates, Yasmin Mathew, Kiyomi Deards, Anissa Ali, Johnnie Blunt. Christina Herd, Derek Mosley, Jeffrey Cruz, Rolando Garcia-Milian, Emmanuel Faulkner.

tion saw a unique opportunity to host a site visit in which former and current scholars were brought together to share experiences, build relationships, and learn from one another-all while showing the current scholars what really goes on in a large research institution.

A planning committee was assembled with librarians from various areas of the libraries, including myself (user experience and assessment librarian), Thomas Padilla (digital scholarship librarian), and Tina Qin (Chemistry librarian) —all of us 2012-14 IRDW Scholars. The planning committee built an itinerary that catered to the interests of the 2014-16 scholars, while also delivering what we jokingly referred to as "medicine"-less glamorous but wholly necessary topics, like models of tenure and promotion-and we tried to incorporate time for small group and one-on-one interactions between scholars and librarians. Surprisingly, the "medicine" on tenure and promotion was received favorably and considered by scholars valuable in preparing them to enter the profession.

Acknowledging that the former IRDW scholars on the planning committee all distinctly remember leaving Purdue utterly exhausted, we tried to balance the schedule and incorporate down-time so as not to completely wear out the scholars. Despite our best efforts, however, sessions ran long, breaks were cut short, and we received feedback that the schedule was at times overwhelming.

In the post-visit survey, sessions on Special Collections and Area Studies Librarianship-favored interests among many of the scholars-received high praise. What seemed to resonate most among the scholars were discussions on diversity and the opportunity to meet people in whom the scholars saw themselves reflected.

A session attended only by the scholars called Cultivating Diversity in Academia with MSU's associate provost and associate vice president for academic human resources, allowed scholars an opportunity to engage in "real-talk" about strategies for success for academic professionals from traditionally underrepresented groups. Scholars felt inspired and empowered by librarians of color at MSU who discussed both their professional 
work as librarians and their advocacy as community members. And, though it feels a little self-satisfying to say it, the current scholars unanimously remarked on the value of being mentored by three IRDW alumni. As one 2015 scholar put it,

They understand where we are and what might be on our minds. I think I can safely speak on behalf of my entire IRDW cohort and say that we're HUGE fans of [the 2012-14 scholars] and are very grateful for their involvement in our site visit. I truly believe they were key to the success of our overall experience.

When I visited Purdue, there were no ARL diversity program alumni at the institution. There were, however, allies and mentors who created a safe space in which I could ask questions without fear of judgment and learn about the reality of working in research libraries. And hearing from one of MSU's visitors that the "open, welcoming, and relaxed atmosphere made [them] feel comfortable to ask questions and participate," I'm both relieved and confident that the MSU libraries lived up to the impressive standards set by Purdue over the last decade.

\section{Conclusion}

Site visits remain a unique and important part of the IRDW program, and their success is predicated on the hosting institutions' significant investment of time, energy, and resources. As we reflect upon the contribution and impact of this component of the IRDW, we would like to thank the host institutions over the last decade who have made these site visits financially possible. We thank key administrators at the libraries of Harvard, MIT, Purdue, and Michigan State for their support of the program, as well as ARL and IMLS. We would also like to thank the decade of IRDW Scholars who enriched the institutions they visited for years to come, and who continue to lead our libraries to success as key administrators themselves.

("Employing field research...," continues from page 328)

In the library field, blogs, webinars, MOOCS, conferences, and even mentormentee partnerships seem readily supported by library administrations. Unfortunately, upon reviewing these programs, rarely did we see mention of the type of field research that we have benefitted from. Field research occurs outside the library, is often crossdisciplinary, and uses mixed methods (such as interviews, observations, participation, and discussion) to gather the most information possible. We hope that this articles serves to demonstrate the merits of a professional development program that encourages a sharing community among institutions. While strengthening the greater librarian community, it also promises to deliver a highly relevant return on investment for your local library.

\section{Notes}

1. Kari Hahn, "Introduction: Position- ing Liaison Librarians for the 21st Century," Research Library Issues: A Bimonthly Report from ARL, CNI, and SPARC 265: 1, 2009.

2. Anne Kenney, "From Engaging Liaison Librarians to Engaging Communities," College E Research Libraries 76, no. 3 (2015) : 386-91, doi: $10.5860 / \mathrm{crl} .76 .3 .387$.

3. Elizabeth Rickert, Page L. McDonald, Marissa Birkmeier, Bryan Walker, Linda Cotton, Laurie B. Lyons, Howard O. Straker, and Margaret M. Plack, "Using Technology to Promote Active and Social Learning Experiences in Health Professions Education," Online Learning 18, no. 4 (2014): 23.

4. Selina A. Berg, Kristin Hoffman, and Diane Dawson, "Perspectives on Integrating Research into LIS Field Experiences in Academic Libraries," Journal of Academic Librarianship, 35 (2009): 591.

(continues on page 346) 